\title{
Protection technique for series capacitor compensated three phase transmission line connected with distributed generation using discrete Walsh Hadamard transform
}

\author{
Gaurav Kapoor \\ Department of Electrical Engineering, Modi Institute of Technology, Kota, Rajasthan, INDIA \\ Corresponding Author: e-mail: gaurav.kapoor019@gmail.com, Mobile: +91-9166868988
}

\begin{abstract}
This study proposes a discrete Walsh Hadamard transform (DWHT) based protection technique for the detection of fault and identification of faulty phase in series capacitor compensated three phase transmission line connected with distributed generation (DG). DWHT has been used for processing of the three phase current signals. To recognize the reliability of the proposed protection technique, it is tested for variation in fault type, fault location, fault resistance, ground resistance and fault inception time. Simulation results of DWHT-based proposed technique exemplify that the proposed technique correctly detects the faults and identifies the faulty phase accurately.
\end{abstract}

Keywords: Discrete Walsh Hadamard transform, distributed generation connected series capacitor compensated three phase transmission line, fault detection, faulty phase identification.

DOI: http://dx.doi.org/10.4314/ijest.v11i3.1

\section{Introduction}

Accurate fault detection and faulty phase identification are the two important aspects of power system protection. Over the years, researchers have been in the search to recognize fast and perfect fault detection and faulty phase identification of the transmission line using various protection techniques, so that the faulted phase can be protected from feasible dangerous effects caused by the fault. Therefore, it is very essential to have a capable fault detection scheme for detecting the transmission line faults and identifying the fault phase. Various fault detection and faulty phase identification schemes have been proposed in the recent years. The survey of some fault detection techniques which are recently proposed by the researchers is described hereafter. An impedance-based fault location method for the protection of a $500 \mathrm{kV}, 350 \mathrm{~km}$ long series capacitor compensated transmission line has been proposed in (Bains et al., 2018). However, the proposed scheme has been analyzed for only single line to ground and double line to ground faults. Current differential protection scheme based on sequence component has been proposed for the protection of transmission lines connected with inverter interfaced generators (Chen et al., 2018). A travelling wave based protection technique has been proposed for the medium transmission lines connected to distribution generation (Davydova and Hug, 2018). Standalone discrete wavelet transform and in conjunction with power spectral density has been used as a very effective tool for fault detection and classification in transmission lines (Guillen, 2018). Fault detection in a series capacitor compensated double circuit transmission line using wavelet transform has been reported in (Gautam et al., 2018). Continuous wavelet transform is applied for the differential protection of transmission line (Govar and Seyedi, 2016). Furthermore, a phase angle of positive sequence integrated impedance (PAPSII) based wide area back-up protection technique has been proposed for the protection of a $400 \mathrm{kV}$ series compensated transmission line (Jena et al., 2017). Location of faults on series compensated double circuit transmission line using distributed parameter transmission line model has been described in (Kang et al., 2015). Mathematical morphology has been used as a very helpful tool for fault detection in a double circuit transmission line (Kapoor, 2018). Wavelet transform is applied for fault detection in a series capacitor compensated three phase transmission line (Kapoor, 
2018). Wavelet transform based protection scheme has been used for double circuit transmission lines (Kapoor, 2018). Recently, one terminal travelling wave based cross differential protection technique has also been used for the protection of double circuit transmission line (Monteiro et al., 2018). Fault location in STATCOM compensated double circuit transmission line using artificial neural network has been presented in (Nagam et al., 2017). In the study presented in (Perera and Rajapakse, 2013), DWTbased single ended protection technique has been investigated for the protection of $500 \mathrm{kV}$ series compensated double circuit transmission line. In the same way, discrete Fourier transform in conjunction with sequence space aided support vector machine classifier are employed for disturbance detection in a series compensated transmission lines (Patel, 2018). Artificial neural network has been utilized for fault classification and location in double circuit transmission line (Saravanan and Rathinam, 2012). Wavelet packet transform has been used for the protection of series compensated transmission line (Samantaray and Dash, 2007). Walsh Hadamard transform has been used (Sharma et al., 2018) for fault detection and faulty phase identification in series capacitor compensated three phase transmission line.

The proposed work reports a single ended discrete Walsh Hadamard transform based fault detection and faulty phase identification technique for wind farm connected series capacitor compensated three phase transmission line against different types of shunt faults with varying various fault parameters such as fault type, fault location, fault inception time, fault resistance and ground resistance. Test results demonstrate that the proposed fault detection scheme effectively detects the fault and identifies faulty phase and the dependability of this scheme is robust to the fault parameters variations.

This paper is structured as follows: the specifications of proposed power system are presented in Section-2. A brief introduction of the Walsh Hadamard transform (WHT) and the proposed WHT-based fault detection and faulty phase identification technique have been presented in Section-3. Test results are analyzed in Section-4. Finally, conclusion of the work is declared in section-5.

\section{Power System Specifications}

Figure 1 depicts the schematic of DG (distributed generation) connected series capacitor compensated three phase transmission line under simulation. The test system consists of a $400 \mathrm{kV}, 50 \mathrm{~Hz}$ DG connected transmission line of $100 \mathrm{~km}$ length. The transmission line is connected to a $400 \mathrm{kV}$ source at the sending end. A wind farm consisting of five wind turbines each having power capacity of 2 MVA is connected at the receiving end of transmission line. The series capacitors are connected at the midpoint of the transmission line. The relay is installed at bus-1 to protect the total length of the three phase transmission line which can be seen in Figure 1. The transmission line model is simulated using MATLAB. Feature extraction of the fault current signals has been done using discrete Walsh Hadamard transform to calculate the Walsh coefficients.

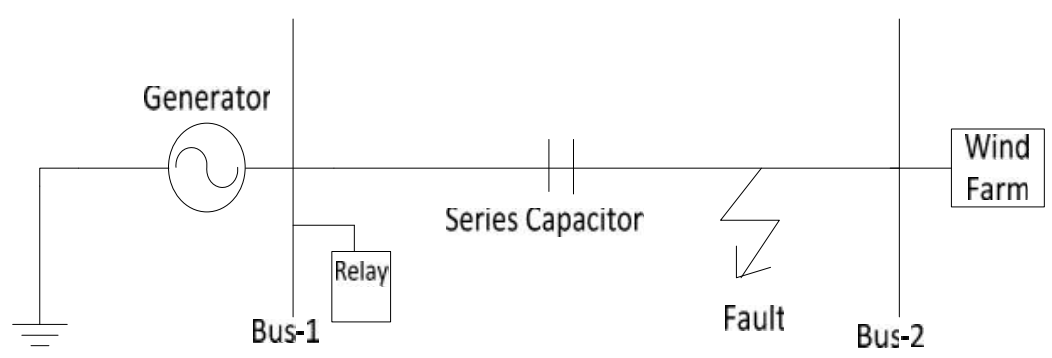

Figure 1. Schematic of proposed simulation model

\section{Proposed Fault Detection and Faulty Phase Identification Technique}

Discrete Walsh Hadamard transform (DWHT) is a well-organized computational mathematical approach which is used to calculate the Walsh Hadamard coefficients. The Walsh Hadamard coefficients can be calculated by using the equation-1 as given below.

$$
y=f w h t(x)
$$

The output variable ' $y$ ' returns Walsh Hadamard coefficients of the input matrix ' $x$ '. The fast Walsh Hadamard transform (fwht) is computed on every column of input matrix ' $x$ '.

The various stages of the proposed technique as shown in Figure 2 are described in detail hereafter.

Step 1 Simulate the test system and generate post fault three phase current signals.

Step 2 Analyze the three phase current signals using Walsh Hadamard transform for feature extraction.

Step 3 Calculate the magnitude of Walsh coefficients for each fault current signal.

Step 4 If the magnitude of Walsh coefficients of the faulted phase is greater than the magnitude of Walsh coefficients of unfaulted phase, then fault else no fault, go to step 1. 


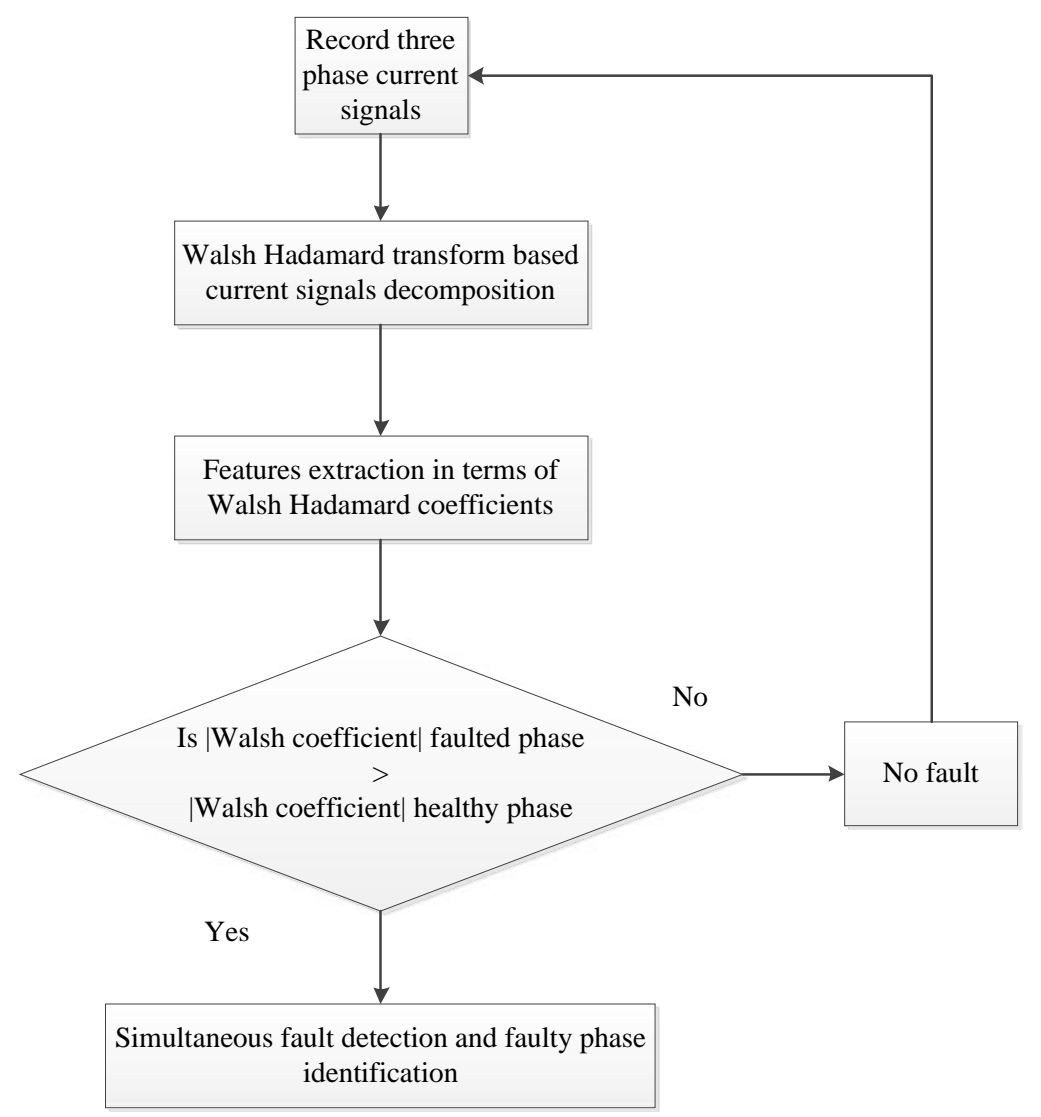

Figure 2. Schematic of proposed technique

\section{Results and Discussion}

To validate the effectiveness of the proposed Walsh Hadamard transform based fault detection and faulty phase identification technique, simulation studies have been carried out for various types of shunt faults. The performance of the proposed technique was investigated with variation in fault type $\left(\mathrm{F}_{\mathrm{T}}\right)$, fault resistance $\left(\mathrm{R}_{\mathrm{F}}\right)$, ground resistance $\left(\mathrm{R}_{\mathrm{G}}\right)$, fault inception time (FIT) and fault location $\left(\mathrm{F}_{\mathrm{L}}\right)$. Following the fault detection and faulty phase identification, some of the simulation results are shown and discussed in the succeeding subsections.

4.1 Response of Proposed Technique for No-Fault: The performance of the proposed technique is analyzed when the transmission line has no fault. The three phase current and voltage waveforms during no-fault are shown in Figure 3 . The discrete Walsh Hadamard transform coefficients of three phase current during no-fault condition can be seen in Figure 4. Thus the performance of proposed protection technique is examined for no-fault operation and the test results are exemplified in Table 1.
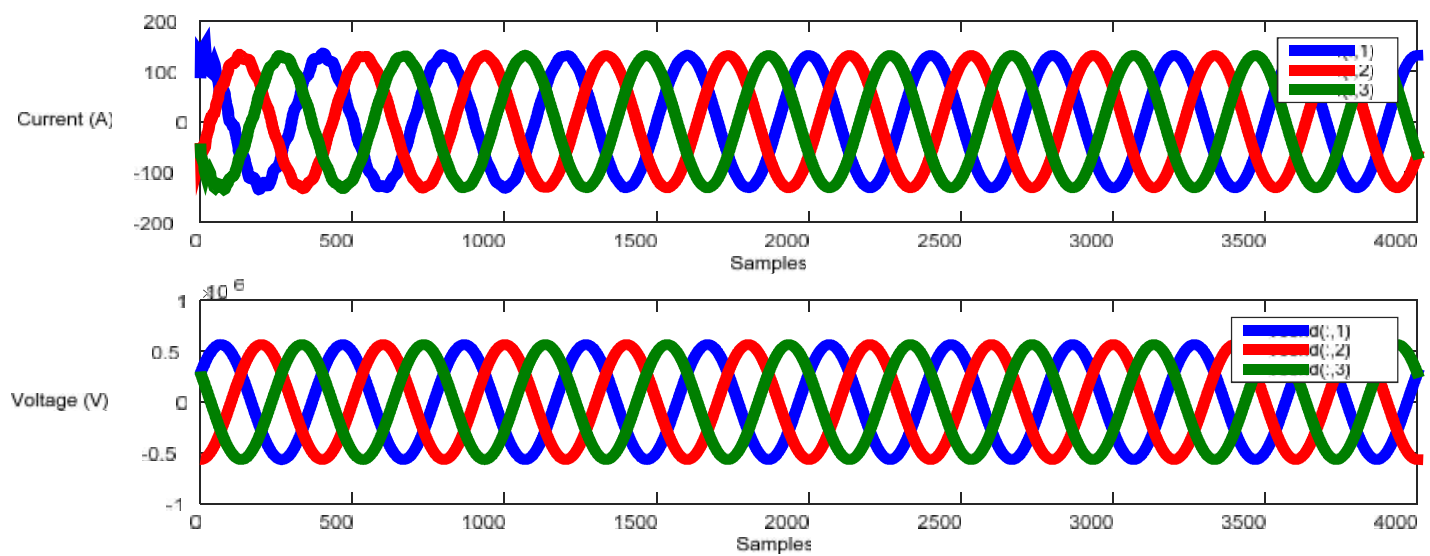

Figure 3. Three phase current and voltage during no-fault 

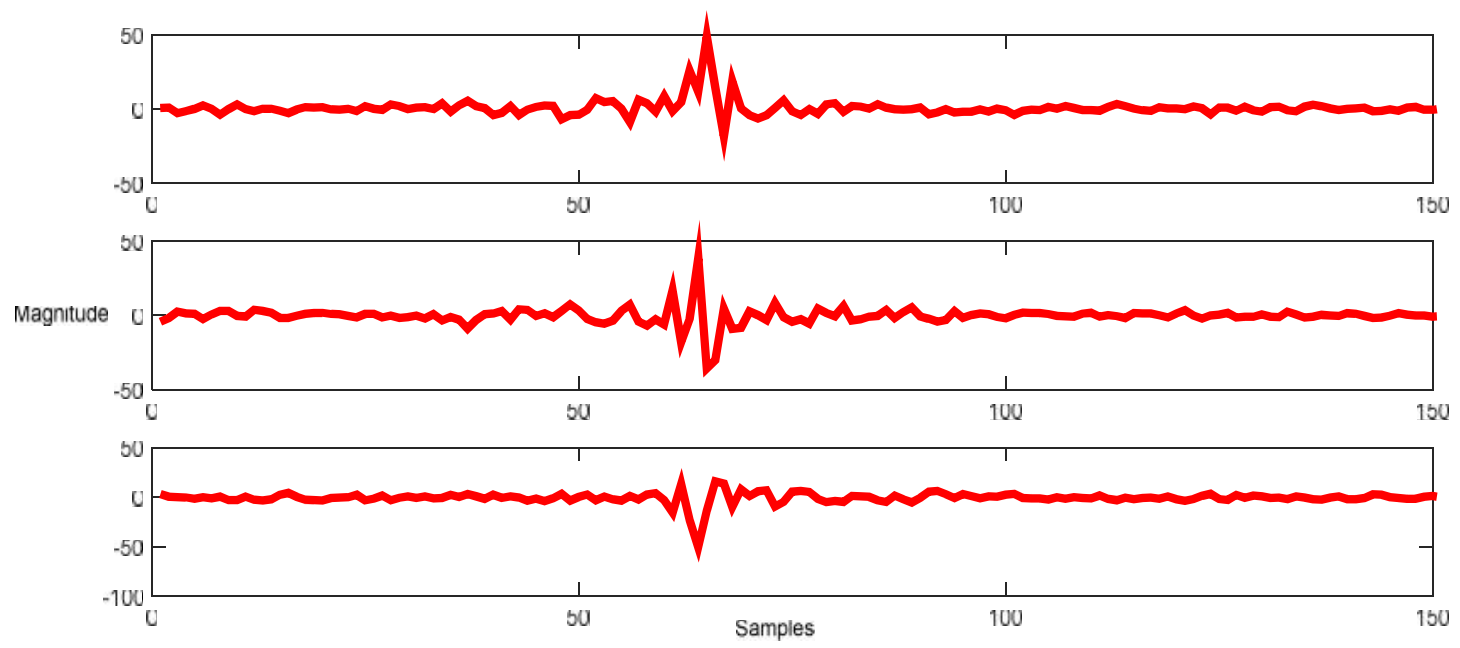

Figure 4. Walsh Hadamard coefficients of three phase current during no fault

Table 1. Test results of proposed technique for no-fault

\begin{tabular}{|c|c|c|}
\hline \multicolumn{3}{|c|}{ Discrete Walsh Hadamard Transform Coefficients } \\
\hline Phase-A & Phase-B & Phase-C \\
\hline 48.8002 & 38.6917 & 21.0011 \\
\hline
\end{tabular}

4.2 Response of Proposed Technique for Variation in Fault Type: The performance of proposed technique has been verified for varying fault type. As an case, the simulation results of proposed technique in case the transmission line is subjected to AG fault at a distance of $50 \%$ from the relaying point at FIT $=0.1$ seconds with $\mathrm{R}_{\mathrm{F}}=\mathrm{R}_{\mathrm{G}}=5$ are depicted in Figures 5-6. For all types of faults, $\mathrm{R}_{\mathrm{F}}$ and $\mathrm{R}_{\mathrm{G}}$ are kept at 5 , respectively; all faults are simulated at $50 \%$ from the relay location, while FIT is selected as 0.1 second. Further, the response of the proposed technique for other types of faults with varying fault type is demonstrated in Table 2. It is clearly examined from Table 2 that the proposed technique correctly detects the faults and classifies the faulty phase accurately and variation in fault type has no significant consequence on the accuracy of the proposed technique.

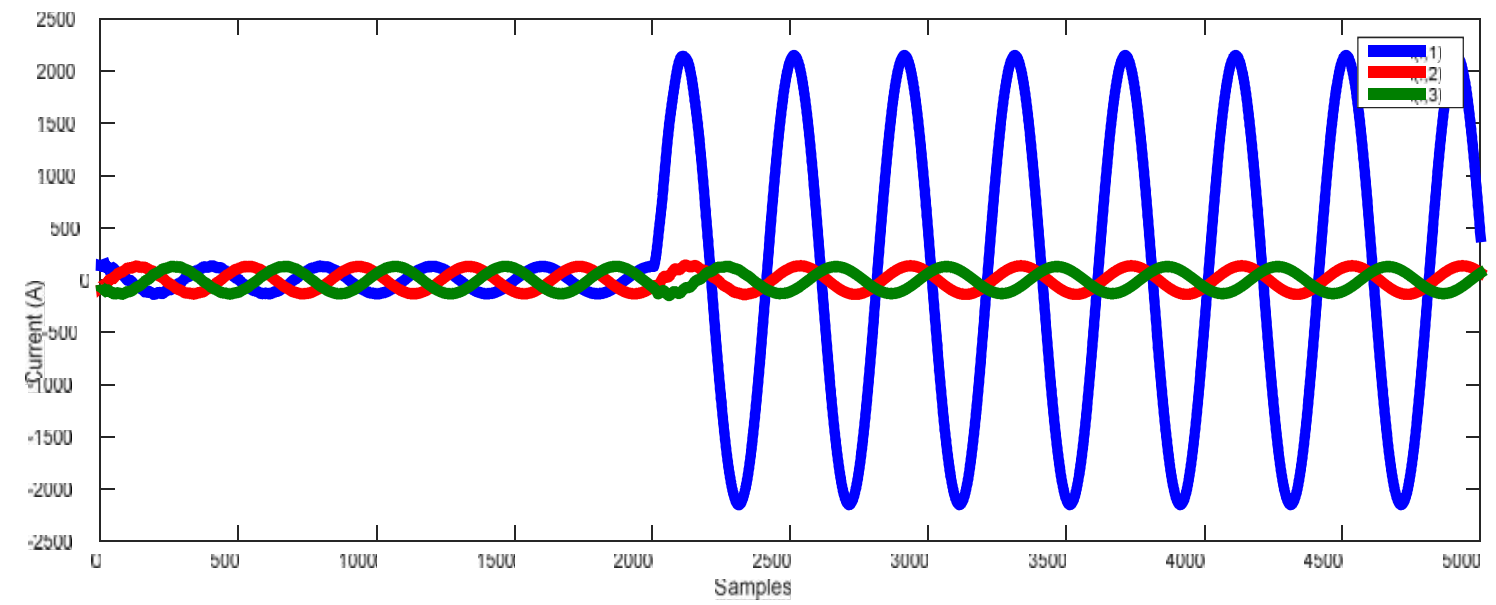

Figure 5. Three phase current during $A G$ fault at a distance of $50 \%$ from the relaying point at $F I T=0.1$ seconds with $R_{F}=R_{G}=5$ 


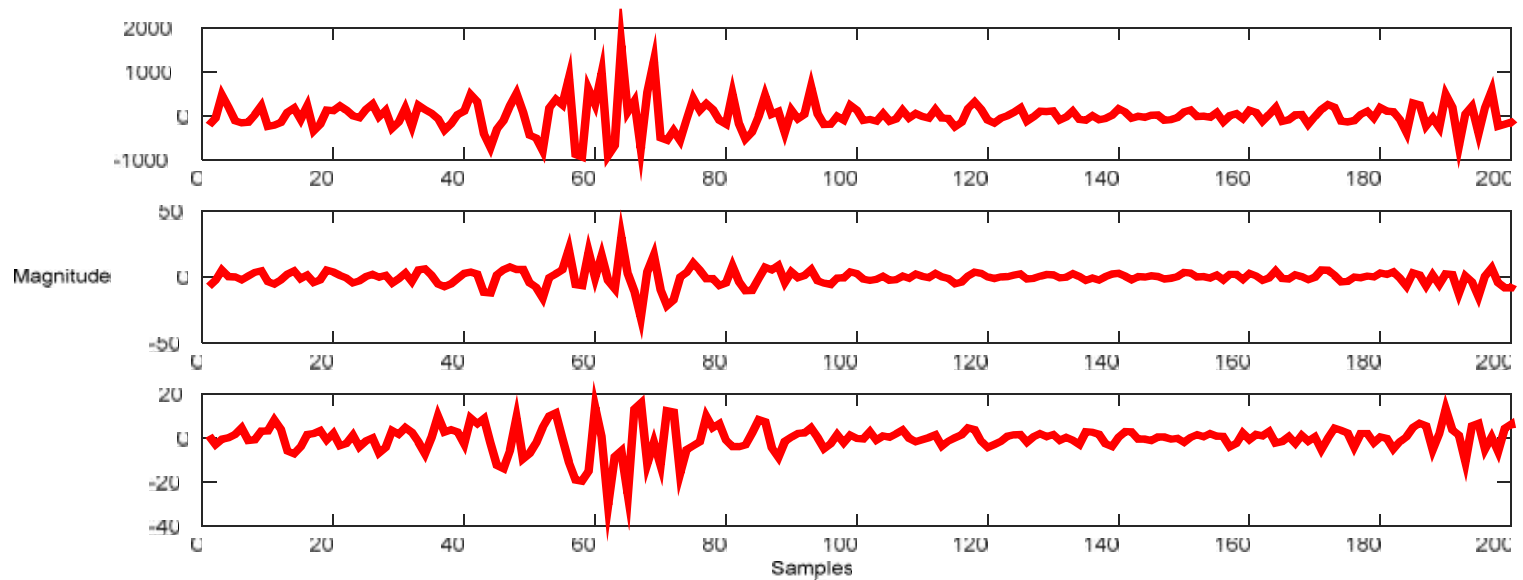

Figure 6. Walsh Hadamard coefficients of three phase current during AG fault at a distance of $50 \%$ from the relaying point at FIT $=0.1$ seconds with $\mathrm{R}_{\mathrm{F}}=\mathrm{R}_{\mathrm{G}}=5$

Table 2. Test results of the proposed technique for variation in fault type

\begin{tabular}{|c|c|c|c|c|c|c|c|}
\hline \multirow{2}{*}{ Fault Type } & \multirow{2}{*}{$\begin{array}{c}\mathbf{R}_{\mathbf{F}} \\
(\quad)\end{array}$} & \multirow{2}{*}{$\begin{array}{l}\mathbf{R}_{\mathbf{G}} \\
(\quad) \\
\end{array}$} & \multirow{2}{*}{$\begin{array}{c}\text { FIT } \\
\text { (S) }\end{array}$} & \multirow{2}{*}{$\begin{array}{c}F_{\mathbf{L}} \\
(\mathbf{k m})\end{array}$} & \multicolumn{3}{|c|}{ Walsh Hadamard Coefficients } \\
\hline & & & & & Phase-A & Phase-B & Phase-C \\
\hline AG & 5 & 5 & 0.1 & 50 & $1.5965 * 10^{\wedge} 3$ & 30.0020 & 15.9438 \\
\hline BG & 5 & 5 & 0.1 & 50 & 18.2437 & $1.3254 * 10^{\wedge} 3$ & 19.0865 \\
\hline CG & 5 & 5 & 0.1 & 50 & 18.8427 & 19.2394 & $1.0656^{*} 10^{\wedge} 3$ \\
\hline $\mathrm{ABG}$ & 5 & 5 & 0.1 & 50 & $1.6605 * 10^{\wedge} 3$ & $1.3126^{*} 10^{\wedge} 3$ & 19.2781 \\
\hline BCG & 5 & 5 & 0.1 & 50 & 14.4548 & $1.9853 * 10^{\wedge} 3$ & $2.2450^{*} 10^{\wedge} 3$ \\
\hline ACG & 5 & 5 & 0.1 & 50 & $2.7114 * 10^{\wedge} 3$ & 16.4624 & $2.1348 * 10^{\wedge} 3$ \\
\hline $\mathrm{AB}$ & 5 & 5 & 0.1 & 50 & $2.0731 * 10^{\wedge} 3$ & $1.8145^{*} 10^{\wedge} 3$ & 17.5038 \\
\hline $\mathrm{BC}$ & 5 & 5 & 0.1 & 50 & 22.3175 & $2.0287^{*} 10^{\wedge} 3$ & $2.0618 * 10^{\wedge} 3$ \\
\hline $\mathrm{AC}$ & 5 & 5 & 0.1 & 50 & $1.2744 * 10^{\wedge} 3$ & 16.6601 & 893.2586 \\
\hline $\mathrm{ABCG}$ & 5 & 5 & 0.1 & 50 & $2.7681 * 10^{\wedge} 3$ & $2.9001 * 10^{\wedge} 3$ & $2.0586^{*} 10^{\wedge} 3$ \\
\hline $\mathrm{ABC}$ & 5 & 5 & 0.1 & 50 & $3.7881 * 10^{\wedge} 3$ & $2.9326 * 10^{\wedge} 3$ & $2.9655^{*} 10^{\wedge} 3$ \\
\hline
\end{tabular}

4.3 Response of Proposed Technique for Variation in Fault Location: The suitability of the proposed technique has been further tested by evaluating its performance for different types of faults at different locations of transmission line. As an example, the simulation results during double line to ground BCG fault triggered at a distance of $60 \%$ from the relay location at FIT $=0.05$ seconds with $R_{F}=10$ and $R_{G}=10$ are depicted in Figures 7-8. For all fault cases, $R_{F}$ and $R_{G}$ are kept at 10 and 10 , respectively; while FIT is selected as 0.05 second. The simulation results related to various fault scenarios with variation in locations of faults on transmission line are reported in Table 3. As can be seen in Table 3, the proposed technique detects all the types of faults correctly and identifies the faulty phase accurately. It can be observed that the DWHT-based proposed technique is robust to the variation in locations of faults.

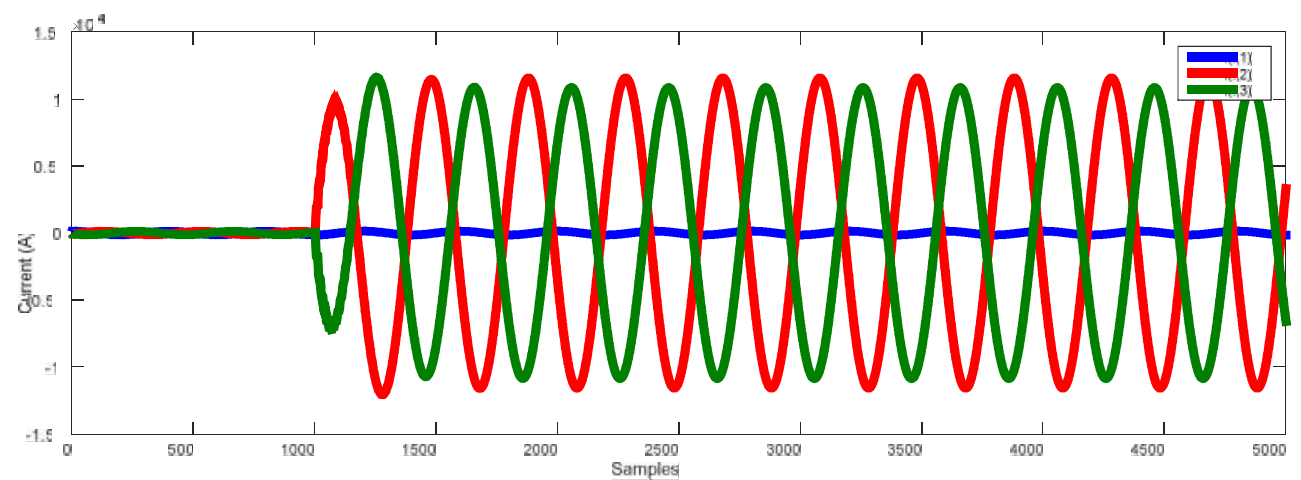

Figure 7. Three phase current during BCG fault at a distance of $60 \%$ from the relaying point at FIT $=0.05$ seconds with $\mathrm{R}_{\mathrm{F}}=10$ and $\mathrm{R}_{\mathrm{G}}=10$ 


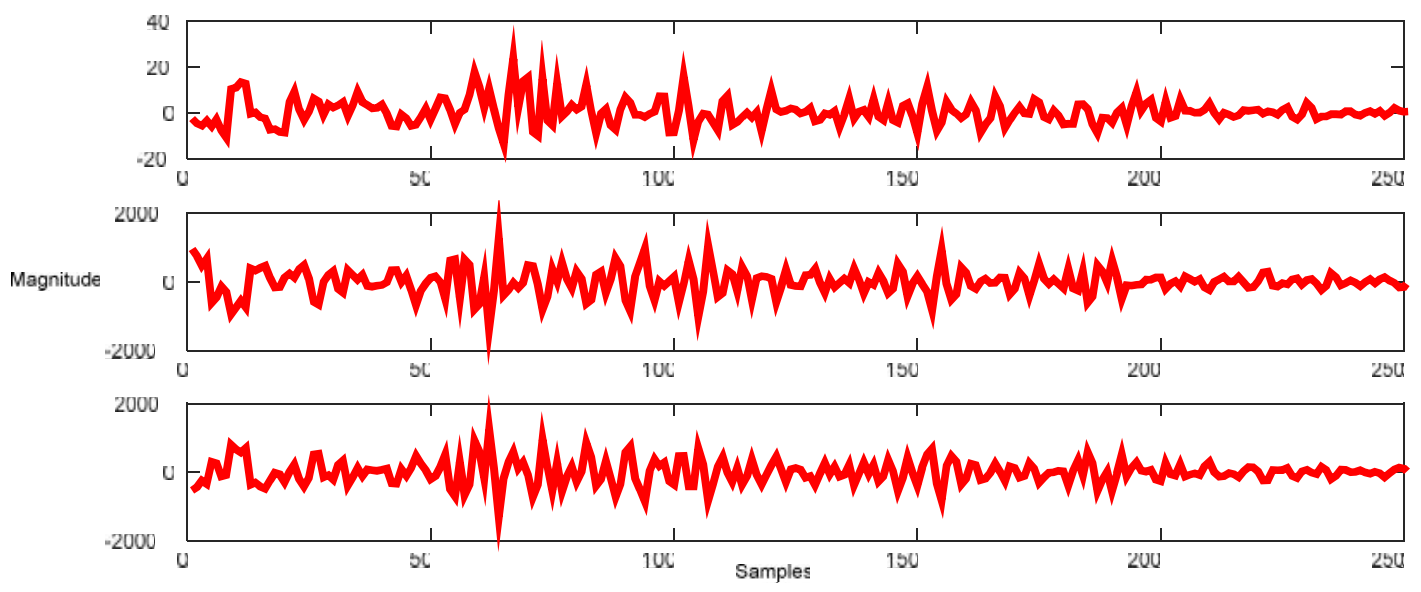

Figure 8. Walsh Hadamard coefficients of three phase current during BCG fault at a distance of $60 \%$ from the relaying point at FIT $=0.05$ seconds with $R_{F}=R_{G}=10$

Table 3. Test results of the proposed technique for variation in fault location

\begin{tabular}{|c|c|c|c|c|c|c|c|}
\hline \multirow{2}{*}{ Fault Type } & $\mathbf{R}_{\mathbf{F}}$ & $\mathbf{R}_{\mathbf{G}}$ & $\mathbf{F I T}$ & $\mathbf{F}_{\mathbf{L}}$ & \multicolumn{3}{|c|}{ Walsh Hadamard Coefficients } \\
\cline { 5 - 8 } & $(\mathbf{C})$ & $(\mathbf{)})$ & $(\mathbf{S m})$ & Phase-A & Phase-B & Phase-C \\
\hline ABCG & 10 & 10 & 0.05 & 15 & $5.1215^{*} 10^{\wedge} 3$ & $3.3775^{*} 10^{\wedge} 3$ & $3.5394^{*} 10^{\wedge} 3$ \\
\hline ABG & 10 & 10 & 0.05 & 30 & $1.3484^{*} 10^{\wedge} 3$ & $2.0937^{*} 10^{\wedge} 3$ & 14.4723 \\
\hline BCG & 10 & 10 & 0.05 & 60 & 23.8565 & $1.2663^{*} 10^{\wedge} 3$ & $1.2442^{*} 10^{\wedge} 3$ \\
\hline AG & 10 & 10 & 0.05 & 90 & 476.5588 & 9.8507 & 15.0616 \\
\hline CG & 10 & 10 & 0.05 & 100 & 12.4304 & 16.0847 & 602.1983 \\
\hline
\end{tabular}

4.4 Response of Proposed Technique for Variation in Fault Resistance: It is very essential to study the impact of fault resistance variation on the precision of the proposed protection technique. To evaluate the impact of fault resistance, various types of faults with $\mathrm{R}_{\mathrm{G}}=0.001$ at a distance of $50 \%$ from the relay location at FIT $=0.2$ seconds have been simulated on transmission line with varying $R_{F}$ and $F_{T}$. To examine the consequence of $R_{F}$ variation, as an example, a three phase to ground fault $A B C G$ is triggered on transmission line at a distance of $50 \%$ from the relaying point at FIT $=0.2$ seconds with $R_{F}=100 \quad$ and $R_{G}=0.001 \quad$. The resulting fault current waveform of three phase current which is recorded at bus-1 is depicted in Figure 9. Discrete Walsh Hadamard coefficients of three phase currents during phase $\mathrm{ABCG}$ fault at $50 \%$ from relay location at FIT $=0.2$ seconds with $\mathrm{R}_{\mathrm{F}}=100$ and $\mathrm{R}_{\mathrm{G}}=0.001$ are exemplified in Figure 10. Test results for various types of faults with different fault resistances are reported in Table 4. It is clearly observed from Table 4 that, for all the test cases, the faults are detected correctly and the faulty phases have been identified accurately. Thus the simulation results follow the immunity of the proposed fault detection and faulty phase identification technique to the variation in fault resistance.

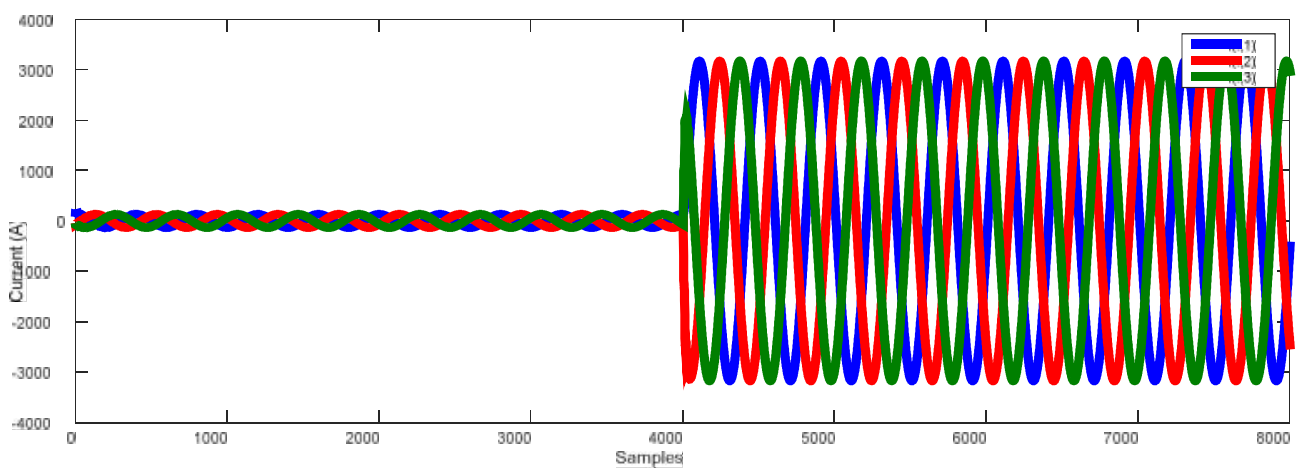

Figure 9. Three phase current during ABCG fault at a distance of $50 \%$ from the relaying point at FIT $=0.2$ seconds with $\mathrm{R}_{\mathrm{F}}=100$ and $\mathrm{R}_{\mathrm{G}}=0.001$ 


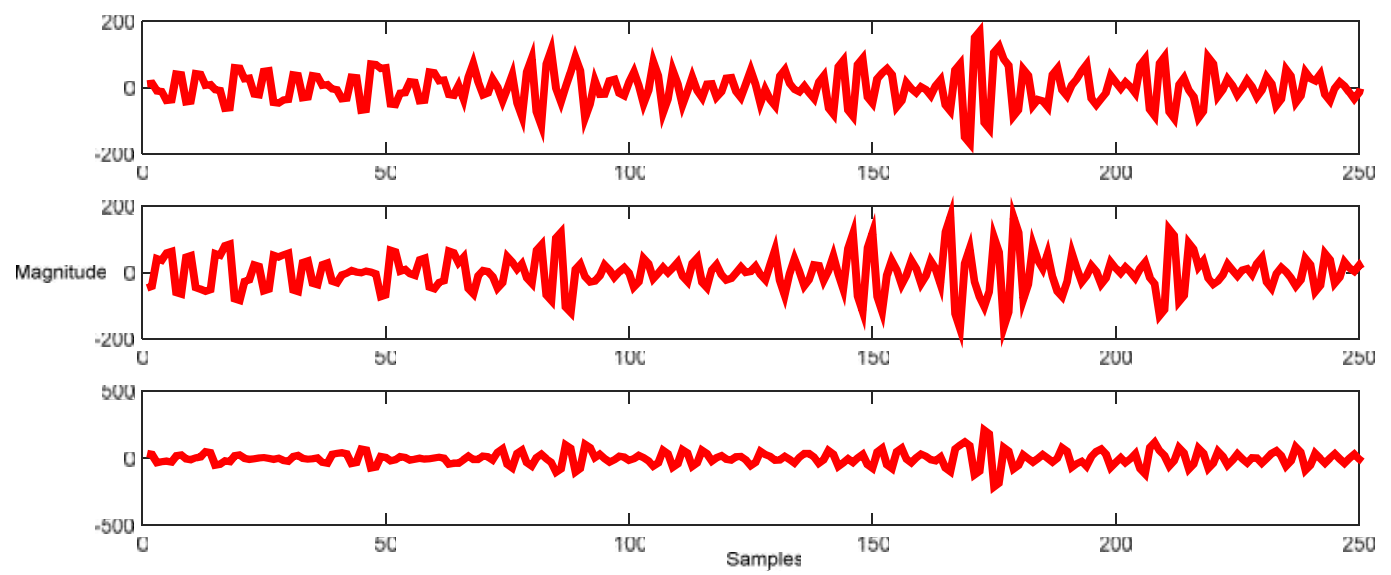

Figure 10. Walsh Hadamard coefficients of three phase current during ABCG fault at a distance of $50 \%$ from the relaying point at FIT $=0.2$ seconds with $\mathrm{R}_{\mathrm{F}}=100$ and $\mathrm{R}_{\mathrm{G}}=0.001$

Table 4. Test results of the proposed technique for variation in fault resistance

\begin{tabular}{|c|c|c|c|c|c|c|c|}
\hline $\begin{array}{c}\text { Fault } \\
\text { Type }\end{array}$ & $\begin{array}{c}\mathbf{R}_{\mathbf{F}} \\
(\mathbf{)}\end{array}$ & $\begin{array}{c}\mathbf{R}_{\mathbf{G}} \\
(\mathbf{)}\end{array}$ & $\begin{array}{c}\text { FIT } \\
(\mathbf{S})\end{array}$ & $\begin{array}{c}\mathbf{F}_{\mathbf{L}} \\
(\mathbf{k m})\end{array}$ & \multicolumn{2}{|c|}{ Walsh Hadamard Coefficients } \\
\hline AG & 1 & 0.001 & 0.2 & 50 & $1.2833^{*} 10^{\wedge} 3$ & 23.8268 & 26.1910 \\
\hline BG & 10 & 0.001 & 0.2 & 50 & 23.5578 & 811.6670 & 15.1014 \\
\hline ACG & 30 & 0.001 & 0.2 & 50 & 801.2852 & 20.4001 & 503.9851 \\
\hline ABG & 60 & 0.001 & 0.2 & 50 & 403.4915 & 634.0735 & 18.0011 \\
\hline ABCG & 100 & 0.001 & 0.2 & 50 & 168.6153 & 168.3640 & 209.2103 \\
\hline
\end{tabular}

4.5 Response of Proposed Technique for Variation in Ground Resistance: It is very important to study the impact of ground resistance variation on the accuracy of the proposed protection technique. To evaluate the impact of ground resistance, various types of faults with $\mathrm{R}_{\mathrm{F}}=15$ at a distance of $40 \%$ from the relaying point at FIT $=0.175$ seconds have been simulated on transmission line with varying $R_{G}$ and $F_{T}$. To analyze the effect of $R_{G}$ variation, a single line to ground fault $B G$ is triggered on transmission line at a distance of $40 \%$ from the relay location at $F I T=0.175$ seconds with $R_{F}=15$ and $R_{G}=2$. The resulting fault current waveform of three phase current recorded at bus-1 is depicted in Figure 11. Figure 12 shows DWHT coefficients. Test results for various types of faults with different ground resistances are summarized in Table 5. It is clearly observed from Table 5 that, for all the test cases, the faults are detected correctly and the faulty phases have been identified accurately. From the simulation results, it can be concluded that the proposed protection technique is insensitive to the variation in ground resistance.

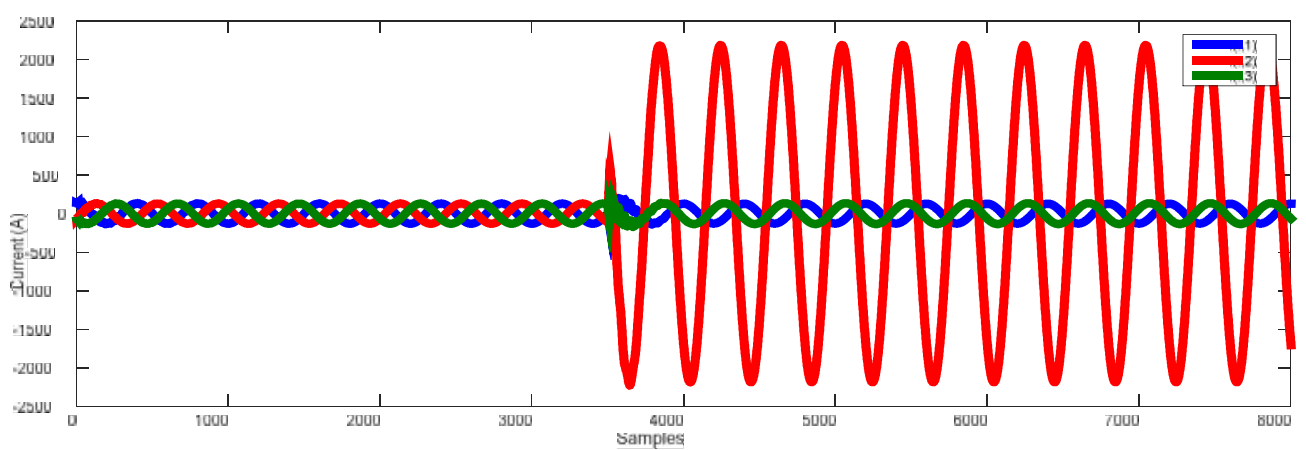

Figure 11. Three phase current during $B G$ fault at a distance of $40 \%$ from the relaying point at FIT $=0.175$ seconds with $\mathrm{R}_{\mathrm{F}}=15$ and $\mathrm{R}_{\mathrm{G}}=2$ 

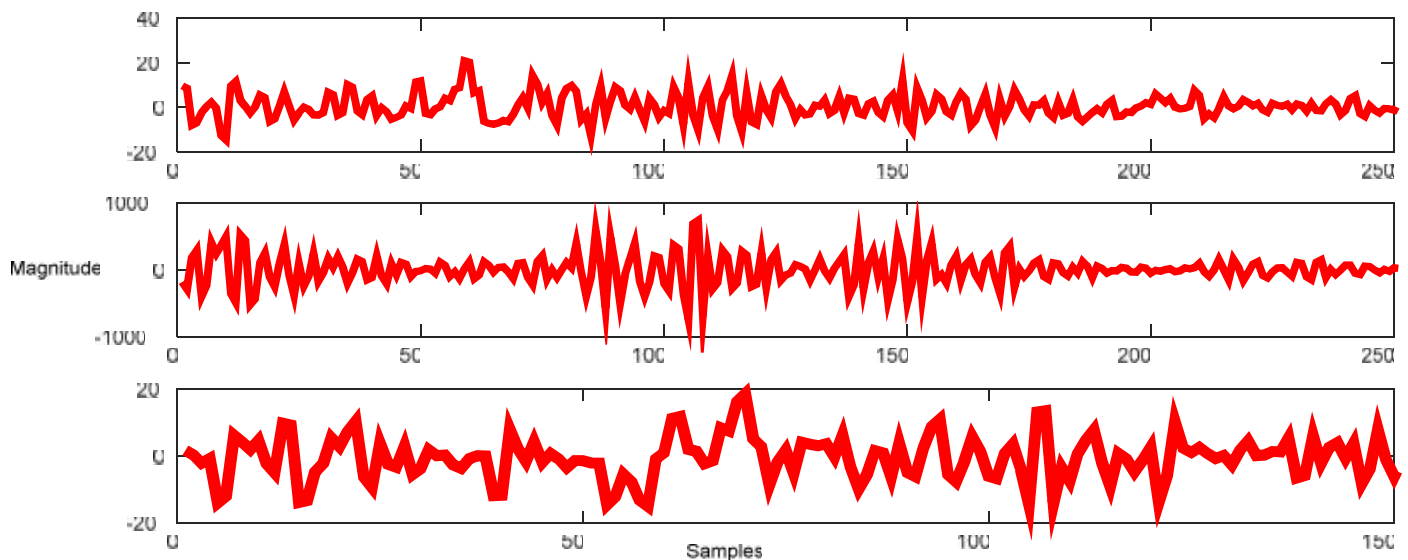

Figure 12. Walsh Hadamard coefficients of three phase current during BG fault at a distance of $40 \%$ from the relaying point at $\mathrm{FIT}=0.175$ seconds with $\mathrm{R}_{\mathrm{F}}=15$ and $\mathrm{R}_{\mathrm{G}}=2$

Table 5. Test results of the proposed technique for variation in ground resistance

\begin{tabular}{|c|c|c|c|c|c|c|c|}
\hline Fault & $\mathbf{R}_{\mathbf{F}}$ & $\mathbf{R}_{\mathbf{G}}$ & $\mathbf{F I T}$ & $\mathbf{F}_{\mathbf{L}}$ & \multicolumn{2}{|c|}{ Walsh Hadamard Coefficients } \\
\cline { 6 - 8 } & $(\mathbf{)}$ & $(\mathbf{)})$ & $(\mathbf{S})$ & $(\mathbf{k m})$ & Phase-A & Phase-B & Phase-C \\
\hline BG & 15 & 2 & 0.175 & 40 & 20.8280 & 739.9101 & 18.5561 \\
\hline ABG & 15 & 15 & 0.175 & 40 & $2.6367 * 10^{\wedge} 3$ & $2.6453^{*} 10^{\wedge} 3$ & 20.4988 \\
\hline ABCG & 15 & 35 & 0.175 & 40 & $1.3708^{*} 10^{\wedge} 3$ & $3.0398^{*} 10^{\wedge} 3$ & $3.1358^{*} 10^{\wedge} 3$ \\
\hline BCG & 15 & 70 & 0.175 & 40 & 13.7842 & $1.2748^{*} 10^{\wedge} 3$ & $1.1795^{*} 10^{\wedge} 3$ \\
\hline CG & 15 & 150 & 0.175 & 40 & 15.7559 & 16.9052 & 170.4078 \\
\hline
\end{tabular}

4.6 Response of Proposed Technique for Variation in Fault Inception Time: The response of the proposed protection technique has been analyzed for variation in fault inception time. In order to evaluate the response of the proposed technique, as an example, a double line to ground fault $A B G$ at a distance of $70 \%$ from the relay location at FIT $=0.1$ seconds with $R_{F}=R_{G}=10 \quad$, is examined, and the simulation results are exemplified in Figures 13-14. The $R_{F}$ and $R_{G}$ are kept constant 10 for all fault cases, and the fault location is set at $70 \%$ from the relaying point. Table 6 reports the performance of proposed technique for various fault cases with FIT variation. As observed from Table 6, the faults are correctly detected and the faulty phases are identified perfectly. Thus, the proposed DWHT-based protection technique is robust to the variation in fault inception time.

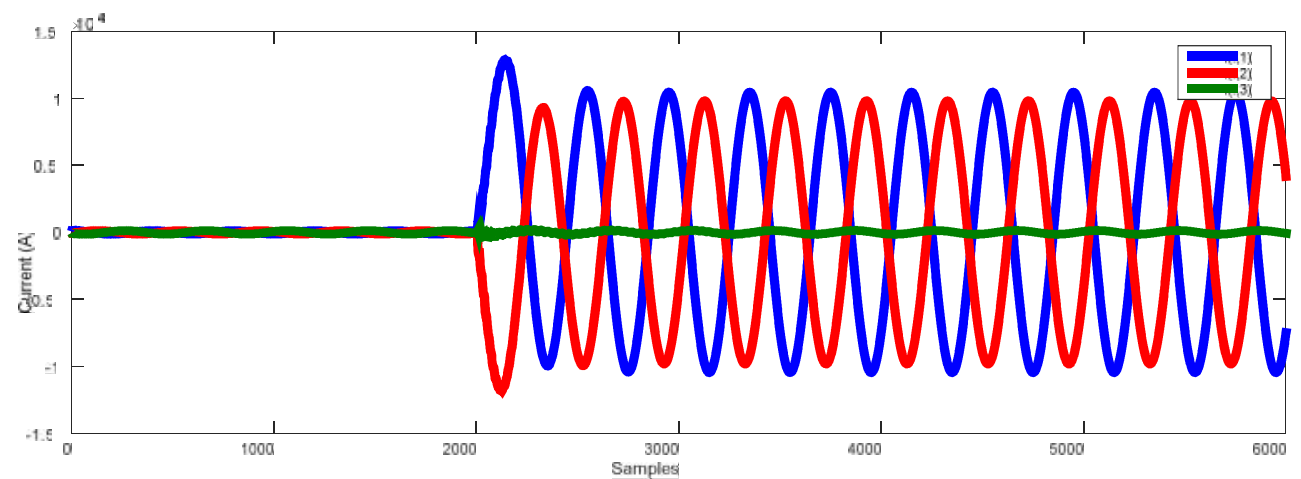

Figure 13. Three phase current during $A B G$ fault at a distance of $70 \%$ from the relaying point at FIT $=0.1$ seconds with $R_{F}=10$ and $\mathrm{R}_{\mathrm{G}}=10$ 


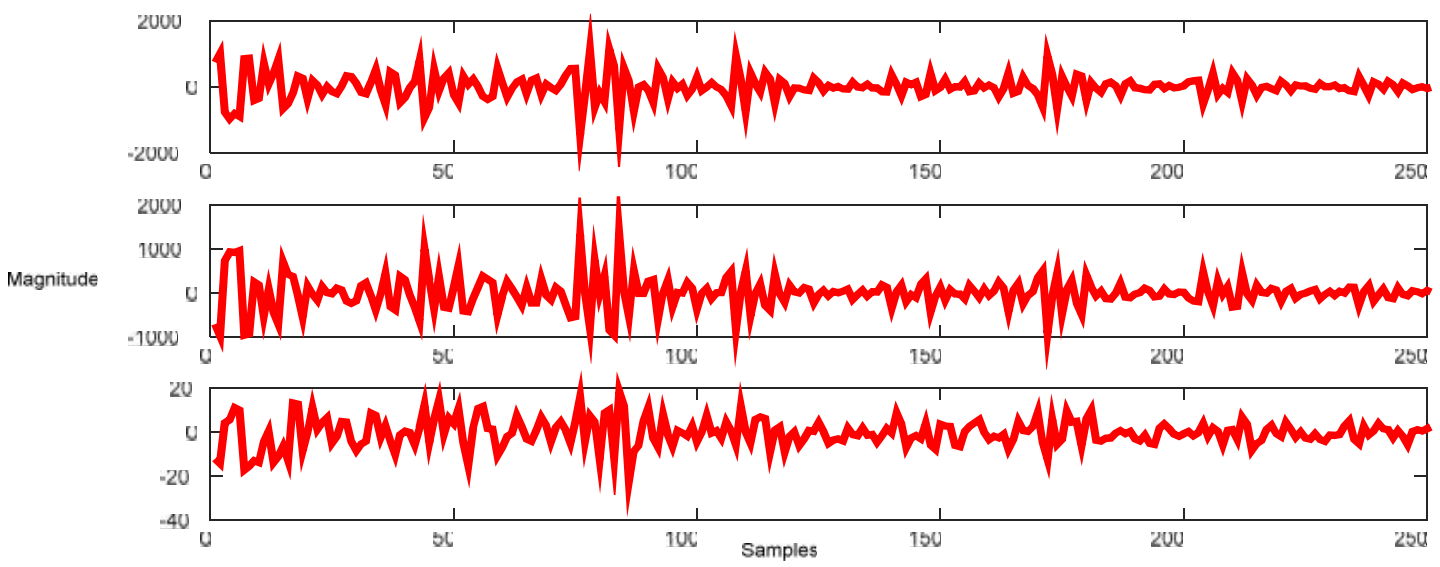

Figure 14. Walsh Hadamard coefficients of three phase current during ABG fault at a distance of $70 \%$ from the relaying point at FIT $=0.1$ seconds with $R_{F}=R_{G}=10$

Table 6. Test results of the proposed technique for variation in fault inception time

\begin{tabular}{|c|c|c|c|c|c|c|c|}
\hline Fault & $\mathbf{R}_{\mathbf{F}}$ & $\mathbf{R}_{\mathbf{G}}$ & $\mathbf{F I T}$ & $\mathbf{F}_{\mathbf{L}}$ & \multicolumn{2}{|c|}{ Walsh Hadamard Coefficients } \\
${ } }$ & $(\mathbf{)}$ & $\mathbf{( ~ )}$ & $\mathbf{( S )}$ & $\mathbf{( k m )}$ & Phase-A & Phase-B & Phase-C \\
\hline ABG & 10 & 10 & 0.1 & 70 & $1.1418^{*} 10^{\wedge} 3$ & $1.3658^{*} 10^{\wedge} 3$ & 18.6230 \\
\hline BCG & 10 & 10 & 0.245 & 70 & 32.6574 & $1.1461^{*} 10^{\wedge} 3$ & $1.1554^{*} 10^{\wedge} 3$ \\
\hline ABCG & 10 & 10 & 0.185 & 70 & $2.1293^{*} 10^{\wedge} 3$ & $1.7897^{*} 10^{\wedge} 3$ & $1.3978^{*} 10^{\wedge} 3$ \\
\hline AG & 10 & 10 & 0.275 & 70 & 572.0140 & 20.0302 & 16.3316 \\
\hline CG & 10 & 10 & 0.15 & 70 & 22.0039 & 23.0903 & 635.8136 \\
\hline
\end{tabular}

\section{Conclusion}

Discrete Walsh Hadamard transform-based protection technique is proposed which detects the fault and identifies the faulty phase. The fault information is captured using characteristics based on Walsh Hadamard coefficients of current signals acquired by DWHT. The three phase current signals measured at the relaying point i.e., at bus-1 only, are used for calculating the DWHT coefficients. The proposed protection technique has been authenticated with numerous types of fault cases with variation in fault type, fault location, fault resistance, ground resistance and fault inception time. Test results exhibit that the proposed protection scheme effectively detects the fault and identify the faulty phase. The future work is planned on execution of the proposed technique on a digital platform (preferably digital signal processor) and assessing the scheme for more practical conditions.

\section{References}

Bains T. P. S., Sidhu T. S., Xu Z., Voloh I., and Zadeh M. R. D., 2018. Impedance-based fault location algorithm for ground faults in series capacitor compensated transmission lines, IEEE Transactions on Power Delivery, Vol. 33, No. 1, pp. 189-199.

Chen S., Tai N., Fan C., Liu J., and Hong S., 2018. Sequence component based current differential protection for transmission lines connected with IIGs, IET Generation, Transmission \& Distribution, Vol. 12, No. 12, pp. 3086-3096.

Davydova N. and Hug G., 2018. Travelling wave protection with disturbance classification for distribution grids with distributed generation, IET Journal of Engineering, Vol. 2018, No. 15, pp. 830-835.

Guillen D., Paternina M. R. A., Bejar J. O., Tripathy R. K., Mendez A. Z., Olvera R. T., and Tellez E. S., 2018. Fault detection and classification in transmission lines based on a PSD index, IET Generation, Transmission \& Distribution, Vol. 12, No. 18, pp. 4070-4078.

Gautam N., Ali S., and Kapoor G., 2018. Detection of fault in series capacitor compensated double circuit transmission line using wavelet transform, Proc. IEEE Int. Conf. Computing, Power and Communication Technologies (GUCON), pp. $769-773$.

Govar S. A. and Seyedi H., 2016. Adaptive CWT-based transmission line differential protection scheme considering cross-country faults and CT saturation, IET Generation, Transmission \& Distribution, Vol. 10, No.9, pp. 2035-2041.

Jena M. K., Samantaray S. R., and Panigrahi B. K., 2017. A new wide-area backup protection scheme for series-compensated transmission system, IEEE Systems Journal, Vol. 11, No. 3, pp. 1877-1887.

Kang N., Chen J., and Liao Y., 2015. A Fault-location algorithm for series-compensated double-circuit transmission lines using the distributed parameter line model, IEEE Transactions on Power Delivery, Vol.30, No.1, pp. 360-367. 
Kapoor G., 2018. Mathematical morphology based fault detector for protection of double circuit transmission line, ICTACT Journal of Micro Electronics, Vol.4, No.2, pp. 589-600.

Kapoor G., 2018. Wavelet transform based fault detector for protection of series capacitor compensated three phase transmission line, International Journal of Engineering, Science and Technology, Vol. 10, No. 4, pp. 29-49.

Kapoor G., 2018. Protection scheme for double circuit transmission lines based on wavelet transform, ICTACT Journal of Micro Electronics, Vol. 4, No. 3, pp. 656-664.

Monteiro B. C. R., Jr. F. M., Lopes F. V. and Silva K. M., 2018. Cross-differential protection for double-circuit lines using current travelling waves, Proceedings of the IEEE International Conference and Simposio Brasileiro de Sistemas Eletricos (SBSE), pp. $1-6$.

Nagam S. S., Koley E., and Ghosh S., 2017. Artificial neural network based fault locator for three phase transmission line with STATCOM, Proceedings of the IEEE International Conference on Computational Intelligence and Computing Research (ICCIC), pp. 1-4.

Perera N. and Rajapakse A. D., 2013. Series-compensated double-circuit transmission-line protection using directions of current transients, IEEE Transactions on Power Delivery, Vol. 28, No. 3, pp. 1566-1575.

Patel U. J., Chothani N. G., and Bhatt P. J., 2018. Sequence-space-aided SVM classifier for disturbance detection in series compensated transmission line, IET Science, Measurement \& Technology, Vol. 12, No. 8, pp. 983-993.

Saravanan N. and Rathinam A., 2012. A comparative study on ANN based fault location and classification technique for double circuit transmission line, Proceedings of the $4^{\text {th }}$ IEEE International Conference on Computational Intelligence and Communication Networks, pp. 824-830.

Samantaray S. R. and Dash P. K., 2007. Wavelet packet-based digital relaying for advanced series compensated line, IET Generation, Transmission \& Distribution, Vol. 1, No. 5, pp. 784-792.

Sharma P., Kapoor G., and Ali S., 2018. Fault detection on series capacitor compensated transmission line using Walsh Hadamard transform, Proceedings of the IEEE International Conference on Computing, Power and Communication Technologies (GUCON), pp. 763-768.

\section{Biographical notes}

Gaurav Kapoor received B.E. in Electrical Engineering from University of Rajasthan, Jaipur, India and M. Tech. in Power System specialization from University College of Engineering, Rajasthan Technical University, Kota, India in 2011 and 2014, respectively. He is an Assistant Professor in the Department of Electrical Engineering, Modi Institute of Technology Kota, India. He has published more than forty papers in various journals. He has also presented many research papers in national and international conferences. His research interests include power system digital protection.

Received January 2019

Accepted February 2019

Final acceptance in revised form March 2019 